\title{
Philosophical and Theoretical Perspectives of Five Laws of Libraries and its Influence on the Library Profession: Issues and Challenges*
}

\author{
Dr. M. Krishnamurthy**

\begin{tabular}{|l|l|}
\hline Contents \\
\begin{tabular}{ll} 
1. Introduction & 6. Role of National Knowledge \\
2. National Information Policy for India & Commission \\
3. Information Science in India & 7. Open Access \\
4. Libraries in the Knowledge Society & 8. Consortia \\
5. Role of Library Associations & 9. Issues and Recent Developments \\
& 10. Conclusion \\
\hline
\end{tabular}
\end{tabular}

\begin{abstract}
The role of information in knowledge society has changed. Library refers to information centre, which is actively involved information collection and promoting use of for the development of individual and society. Modern libraries are the centres of interaction for all interested in accessing information and in participating in the marathon of the present competitive age. Information and a conducive environment of its free flow is a vital tool in all forms of human endeavour. It is the link pin of national development. For a nation to develop it needs to have and provide relevant, updated and adequate information on food security, health, democracy, population, education, family planning, youth empowerment, gender quality, environment etc. The information intermediaries are the persons to modulate these complexities and find match between the information sources and users needs to satisfaction of Ranganathan's law: Books are for use; Every reader his/her book; Every book its reader; Save the time of the reader; Library is a growing organism. The relative importance of these norms in modern context has been evident from experience, study, observations, discussions, etc., and only by scientists and technologists, but also by managers, planners, and policy makers. They recognize the usefulness of information in the performance of their needs information needs. Libraries are therefore proper management, provision and dissemination of such information. It is clearly visible in the contemporary context, that the libraries in the knowledge society are much more than the book depositories This article looks at the theory/practice divide in library and information science and particularly Ranganathan's contributions, basic statements remain as valid in substance if not in expression as -to-day as when they were promulgated, concisely representing the ideal service and organizational philosophy of libraries today.
\end{abstract}

Keywords: Five Laws of Library Science, Philosophcial Approach, Ranganathan.S.R, Library Development in India, Relevance of Five Laws of Library Science

* This article was originally presented at the International Seminar Commemorating the 80th Anniversary of Ranganathan's "Five Laws of Library Science," held in Daejon, Korea, 20 October 2011.

** Associate Professor of Information Science at Documentation Research and Training Centre, Indian Statistical Institute, India

논문접수일자: 2011년 10월 12일최초심사일자: 2011년 11월 3일게재확정일자: 2011년 11월 27일 한국문헌정보학회지, 45(4): 271-286, 2011. 〔http://dx.doi.org/10.4275/KSLIS.2011.45.4.271〕 


\section{Introduction}

S. R. Ranganathan (1892-1972) was considered the father of library science in India. He developed which has been widely accepted as the definitive statement of ideal library science. His five laws of library science (1931) is a classic of library science literature, as fresh today as it was in 1931. These basic statements remain as valid in substance if not in expression as -to-day as when they were promulgated, concisely representing the ideal service and organizational philosophy of libraries today.

Information is a socio-economic product. Organizations, generation, transfer and use of information is helpful in shaping the socio-economic development of any nation. The value of information is not absolute but relative value determined by the nature of and the situation of consumer of information that has significance will be higher potential value of information is of primary importance in satisfying group and individual information needs. As it becomes more specific and focuses more specific concerns, information acquires value. Hence information in order to meet a need and acquire increased value must be provided in the appropriate format and level. Information exists in a complexity continuum. The needs of a target users serviced by a library and information centre is also a complexity continuum. The information intermediaries are the persons to modulate these complexities and find match between the information sources and users needs to satisfaction of Ranganathan's law: Books are for use; Every reader his/her book; Every book its reader; Save the time of the reader; Library is a growing organism. The relative importance of these norms in modern context has been evident from experience, study, observations, discussions, etc., and only by scientists and technologists, but also by managers, planners, and policy makers. They recognize the usefulness of information in the performance of their needs information needs. The positive impact of information on Research and Development, innovation, decision making etc and a fair number of writings on the value of information have been presented in several case studies. However, in order to make this information useful are has to embarking on a system of information flow in a society. It would focus part of societal activities of a nation. The role of information in knowledge society has changed. Library refers to information centre, which is actively involved information collection and promoting use of for the development of individual and society. Modern libraries are the centres of interaction for all interested in accessing information and in participating in the marathon of the present competitive age. Information and a conducive environment of its free flow is a vital tool in all forms of human endeavour. It is the link pin 
of national development. For a nation to develop it needs to have and provide relevant, updated and adequate information on food security, health, democracy, population, education, family planning, youth empowerment, gender quality, environment etc. Libraries are therefore proper management, provision and dissemination of such information.

\section{National Information Policy for India}

\subsection{Some Background}

India is a land of one billion people-about one sixth of the world. Our civilization dates back to many thousands of years. India is a land of many religions, many cultures and many languages. With the achievement of independence in 1947, India made rapid progress in Librarianship. S. R. Ranganathan, was very much in the fore front of the development of librarianship in India. Before independence he published post-war reconstruction of libraries in India. Sir John Sargent, then education advisor to the government of India, appointed a national library committee in 1947 with Ranganathan as one of the members. Various other committees were also appointed to examine libraries in India. The appointment of the University Education Commission in 1948 was the first major event after independence, with S. Radhakrishnan then, president of India as its chairman. The University Grants Commission (UGC) was appointed in 1953 for the development of the university libraries. Later the Education Commission was appointed (1964-66) for the benefit of university libraries. The government appointed the Advisory committee for libraries in 1957, which strengthen the development of public libraries in India. These foregoing committees and commissions made recommendations that changed finances, services, working conditions of different types of libraries and their staff. In 1951 the U.S government, through public law A80 plan and a wheat loan program of the education exchange assisted the eighty eight university and research libraries in collection development.

The development of public libraries began with independence in 1947 to the credit of S. R. Ranganathan. The Madras Public Library Act of 1948 was the first library legislation to be enacted in independence India for providing public library development could be achieved through passing library acts in various states. After madras, Andhrapradesh in 1960, Karnataka in 1965, and Maharashtra in 1967. Other to follow were west Bengal in 1979, Kerala in 1989, Haryana in 
1989 and Goa in 1993. A significant development of the post independence era was that in 1948 the Imperial library in Calcutta became the National Library of India. The Delivery of Books (public libraries) Act 1954, as amended in 1956, had the foundation for national depository centres. They included the National Library in Calcutta, Asiatic Society in Bombay, Connemara Public Libraries in Madras and Delhi Public library. The Delhi public library, a joint government of India and UNESCO pilot project, was founded in 1951. Later University Grants Commission started Information and Library Network (INFLIBNET) Centre is an Autonomous Inter-University Centre (IUC) of university Grants Commission involved in creating infrastructure for sharing of library and information resources and services among Academic and Research Institutions. INFLIBNET works collaboratively with Indian university libraries to shape the future of the academic libraries in the evolving information environment.

\section{Information Science in India}

\subsection{Library is a Growing Organism}

Library is a growing organism -- S. R. Ranganathan's fifth law of library Science. The postulate will hold good for the fares cable futures, especially in the term growing is interpreter in the sense of biological growth, which signifies a living organism, renewing constantly its internal system cells, evolving and adopting itself to the changing environment library here denotes the species of institutional forms established by society to manage information resources to provide information to people, that is for the institutionalizing of information services. Its internal system is composed of information sources, personal, information processing techniques, facilities and equipment, and its outputs, information product and services, together with its organizational structure and management, in other words, the hard ware, system, brain ware and firmware. In the second half of the present century, we notice that the establishment of several research institutes, universities and information centers. Responding to the need for information support to national development plans, their implementation, monitoring and evaluation at sectoral, national and international levels. His five laws are seen as the basic philosophical framework of librarianship by many in the profession. Facet analysis and subject structuring get substantial references, including in computer generation of thesaurus, deep structure indexing systems, and expert systems design. In discussion on rules and codes for cataloguing Rangananthan's classified code and cannon for cataloguing 
get substantial notice. History of Library development in India, Professional association, reference service, library administration etc, among are the other development took place in India.

The Significant development in providing documentation service first took place in special libraries. The development of special librarianship in India has been to be large extent sponsored by the government. During the post independence period by the scientific and technological progress has been the main concern of India for the development of the Industrial sector. The setting of national Information System (NISSAT) in 1977 is a landmark in India's science and technology information system. Documentation service is a post independence activity. According to S. R. Rangathan, "The credit of having started a systematic continued large scale democratic work, for the time in Indi, goes to the forest Research Institute, Dehradun. However, the most significant development of the area of documentation was the founding of the India National Scientific Documentation Centre (INSDOC) at New Delhi in 1952 under the sponsorship of the government of India and UNESCO Again, he saw that a national model was required, and played an important role in establishing INSDOC, one of the pioneer national organizations devoted to the control of the growing flood of scientific and technical documents, in the interest of the nation as a whole. In 1964, INSDOC started advanced training in documentation. The Documentation Research Training Centre was established at Bangalore in 1962 under the leadership of S. R. Ranganathan for providing advanced training in documentation. Indian Association of Special Libraries and Information Centre (IASLIC) was started in 1955. The library and information division of the Bhabha Atomic Research Centre, The Defence scientific Information Centre (DESIDOC) and National Medical Library, National Aeronautical laboratory Information Centre. Several other information centres of national importance are on the anvil. Later Information and Library Network (INFLIBNET) Centre is an Autonomous Inter-University Centre (IUC) of university Grants Commission involved in creating infrastructure for sharing of library and information resources and services among Academic and Research Institutions. INFLIBNET works collaboratively with Indian university libraries to shape the future of the academic libraries in the evolving information environment.

\section{Libraries in the Knowledge Society}

Information and a conducive environment of its free flow is a vital tool in all forms of human endeavour. It is the link pin of national development. For a nation to develop it needs to have 
and provide relevant, updated and adequate information on food security, health, democracy, population, education, family planning, youth empowerment, gender quality, environment etc. Libraries are therefore proper management, provision and dissemination of such information. It is clearly visible in the contemporary context, that the libraries in the knowledge society are much more than the book depositories. Libraries are not just performing traditional tasks in a new environment such preserving our cultural heritage but provide greatly extended services to millions of users like students, researchers and members of the public as a whole. Libraries are also able to access a huge range of high quality information. They are fast becoming treasure-houses of digital content as well as creators of digital content themselves. Libraries have key role to play in underpinning learning in its broad sense, both as a formal activity in an institution and informally with in the community. Public libraries are the focal points for local community, stimulating learning.

In the global knowledge economy of the twenty first century policy challenges will require it to use knowledge more effectively to raise the productivity. This is because the application of knowledge as manifested in areas such as entrepreneurship and innovation, research and development, and people's education and skills levels, is now recognized as one of the key source of growth and competitiveness in the global economy. Although knowledge has always been at the care of any country's development process, increased speed in the creation and dissemination of knowledge is making it even more important in development strategy. Knowledge is more important today than ever, as the twin forces of globalization and technological advances are spurring an ongoing knowledge revolution. At the same time, of course, a revolution information and communication technology (ICT) is increasing worldwide interdependency and connectivity. Consequently, countries competitiveness depends more than even on their ability to access, adapt, utilize and create knowledge. Knowledge has become the key driven of economic competitiveness and success. Improved knowledge has led to increasing productivity, and the creation and application of new technologies has increased the range of library services and products and brought revolutionary change to virtually in library applications.

Efficient utilization of knowledge creates wealth in the form of better health, education and infrastructure. Knowledge society has two components-societal transformations built an education, healthcare, agriculture, governance and wealth generation. Creative capacity, innovative talent and ability to determine the relevance of the products and service are the most important indicators of the knowledge society. All the countries in the world are moving towards being knowledge 
societies and there by reiterating that they are the learning societies. In a knowledge society learning and education have a very high priority and in the process most of the governments spends significant amount of their budget to promote higher learning and education. To be in tune with the growing and mature knowledge society, various professional institutions will establish the associations to demonstrate their activities.

\section{Role of Library Associations}

There are few library associations in different part of India whose contributions to the development of national consciousness were immense and deserve to be remembered by the future generation of library professionals. Association is a yardstick for measuring the growth of awareness of problems and needs of a country with in a given time. Founding fathers of Librarianship in India have very clearly visualized the commitment of the associations to the following vital aspects;

1. The furtherance of library movement in India

2. The promotion of the training of librarians

3. The improvement of the status of librarians

Some of these activities are well reflected in the overall performance of Indian Library Association, Bengal Library Association, Andhra Pradesh Library Association, Andhra Pradesh Public Library Association, Madras Library Association, Karnataka Library Association, Punjab Library Association and Kerala Library Association. There was time when the libraries and library associations joined hands with government to propagate government policies and programmes. Some of the Library and literary associations in India. Such objectives of the professional associations have taken a back stage today, due to more conservative and materialistic approach adopted by them of late.

The associations in their formative period were adorned by the men of eminence who have dedicated themselves to the cause of national development. They were the great visionaries supported by very committed people who were the first rate scholars in their own field of activity and worked to fulfil the objectives set by the elders. 
Library Associations and Societies, Academies, Trusts and Foundations have endeavoured a lot to give a new face-lift to the professionalism in India. Presently, there are associations and societies representing different types of Libraries and Information Centres. Most of them are making consistent efforts to develop the associations on the pattern of the associations of United States of America and United Kingdom. Many of them are emulating the world-recognized associations. But, there are some constraints of peculiar nature, which are coming in the way of progress.

In spite of the success story of the achievements of the library associations, there are some lacunae in the library development programmes in India. The reasons for this are many. India is a vast country having different political parties both at the centre and the states. The fluctuations in governments are very common. Whatever the best work done in promoting the library development with the mediation of the Associations may or may not be continued. Hence the development of the libraries is hampered. Even the Associations have inculcated the spirit of the political system and more involved in elections and making efforts to gain the power. This has resulted in slowdown of the development. Associations at the National level like ILA, IASLIC, and SIS have done some noticeable changes and developments. They are hardly continued by the next group of office bearers. They may go for their own strategies. Therefore the Associations have to have a plan of action to withstand the test of the time.

It is strongly felt that the Associations should take a broad outlook and consider the following aspects in order to gain the national and international recognition;

( i ) Maintaining the task force of members to analyze professional problems and to find ways to solve them.

(ii ) Strive for representing the government formed task forces to form a part of the nation building.

(iii) Conduct tests and inspection and grading services to help and ensure professional satisfaction.

(iv) Developing standards, grade-and-quality labelling to help the professionals to choose right products to serve the needs of the users.

( v ) Workout the method of operation to introduce accreditation and assessment of Library and Information Science education and training.

(vi) Formulation of lobbying group to interact with the administrators, management, bureaucracy and the local governments to impress upon them the need for giving the library due 
consideration of essential services.

(vii) To workout the practical and viable norms and standards for LIS programmes through distance mode of education.

(viii) To formulate national Information Policy and advocate for its implementation.

In this direction Library Associations in India have made very marginal progress. National Associations have the Special Interest Groups in very vital aspects of the professional matters like Library Legislation, Academic Libraries, Special Libraries, Government Libraries, LIS Education and Research, Information Technology Application etc. But the aspects of Standardization, Accreditation, and Curriculum Development providing choice based credit system, interdisciplinary research, collaboration and linkage with national and internationals organizations and associations etc., are not given serious thought. Time is ripe and the new millennium demands that the appropriate action be taken by the association in India in this regard.

Padmashri Dr. S.R. Ranganathan, the father of library movement in India has guided the activities Madras Library Association since its inception with his multifaceted professionalism. His contribution to ILA and many other regional library associations are worth appreciation. He was responsible for inspiring innumerable followers all over the country to carry the mission forward. The achievement of ILA, IASLIC, RRLF and SIS have set a good trend of bringing our publications, organizing seminars, conferences and workshops, promoting education and research encouraging the regional and local level associations. Comparatively speaking much more remains to the achieved by these organizations.

\section{Role of National Knowledge Commission}

Information society is witnessing the power of information and knowledge' at its best. Today the information is most valuable and sought after commodity and a resource. It is prime mover of the society. Production, distribution and consumption of information has multiplied to astronomical figures. Knowledge is now an international public good and its benefits extend to all those who can access it irrespective of political boundaries. Investment in its generation gives much higher returns than in production of industrial goods. Recent economic theories indicate that growth of knowledge can generate endless potential for economy. Knowledge growth is brought out 
by Institutions of higher education and research through R \& D. Libraries help generate more knowledge by disseminating it. Investments in Knowledge creation and dissemination is becoming an engine of economic growth, sophisticated and systematic theoretical knowledge aides advances in every social sphere. Providing access to knowledge is the most fundamental way of increasing the opportunities and reach to individuals and groups. Therefore, means must exist for individuals who have the ability to receive and comprehend knowledge to readily obtain it. This also includes making accurate knowledge of the state and its activities available to the general public. The role of libraries in providing widespread and inclusive access to knowledge is widely acknowledged. In today's context, a library has to play two distinct roles- to serve as a local centre of information and knowledge, and to be a local gateway to national and global knowledge. To achieve this goal, existing libraries must modernize their collections, services and facilities, become more pro-active, and collaborate with other institutions, agencies and non-governmental organizations (NGOs) in order to develop a community based information system. Recognizing that the Library and Information Services sector needs immediate and sustained attention in order to fulfil its potential, National Knowledge Commission constituted a working group on libraries, composed of experts in the area. The Working Group formulated its recommendations after holding extensive discussions with a wide range of professionals. National Knowledge Commission recommendations on LIS were submitted to the Prime Minister in 2006. The need to user modern information and communication technology to meet the challenging needs of LIS sector has been widely recognized. Some of the issues considered by National Knowledge commission include institutional framework of libraries, networking LIS education, training and research; modernization and computerization of libraries, maintenance of private and personal collections, and staff requirements to meet changing needs (National Knowledge Commission 2006).

\section{Open Access}

In the Information Society, free flow of information is a fundamental principle for bridging the knowledge gap between privileged and under privileged communities. Social inclusion and economic empowerment are also achieved in a society where citizens have universal access to information and knowledge, ranging from public information to specialized or customized information related to one's profession vocation or culture. Open access to information and knowledge is a key contributor in providing universal access to information and knowledge. Thus, the open 
access movement in developed countries which already have necessary information infrastructure. With the availability of advanced information communication technology (ICTs) and by building up necessary information infrastructure in South Asia, particularly in India, this sub-region becomes an active contributor to global open access literature. Traditional knowledge, presently available amongst, indigenous people in folklore or other forms, is now being explored and documented. The digitization of century old publications and rare documents institutions access their sub-region to preserve them and make them accessible through networks of digital archives. E-content is are being produced by members of different communities, facilitated by certain development organization like Inflibnet, University Grants Commission, Council of Scientific and Industrial Research, Indian Council of Medical Research and other research institute.

\section{Consortia}

Over the last four to five years, academic, public, and special libraries in India have been joining together to negotiate collective licenses for the use of electronic journals and other forms of digital information, with consortia sales fast becoming the predominant means of negotiation access to scholarly journals. The e-publishing has brought a revolution in journals publications subscription, access and delivery mechanism. The major research and development institute like Council of Scientific and Industrial Research (CSIR), Indian Space Research Organization (ISRO), Defense Research and Development Organization (DRDO), Indian Council for Agriculture Research (ICAR) Indian Council for Medical Research (ICMR), and other institutes like INFLIBNET, IIM, IITs, and HELINET initiated by Rajiv Gandhi University of Health Sciences spend annually a huge amount of Rs 200 crores towards acquisition.

\section{Issues and Recent Developments}

One of the world's largest economies, India has made tremendous strides in its economic and social development in the past two decades and is poised to realize even faster growth in the years to come. Rapid advances in ICT are dramatically affecting the acquisition, creation, dissemination, and use of knowledge, which is turn, affects economic and social activities, including how service providers and governments are organised and how they perform the functions. It 
is clear that developing countries like India must invest in building their information infrastructure. Particularly users in developing countries example:

\subsection{Information identification service}

Resource Preservation is becoming an increasingly important role for Librarians. Most of information resources in developing countries are published in informal channels. The resources that abound in the Indigenous knowledge system are hardly documented. And as the custodians of these knowledge resources die a generation of oral history, literature and culture disappear. Developing countries library schools and librarians in specialized institutions like African Studies Institutes have the critical challenge to use the emerging technological and digital systems and tools to preserve.

\subsection{Networks}

It must be emphasized that legislative and related libraries have something to give and gain in a participatory network environment. They can share their books, journals, recent additions, newsletters and legislative decisions, current events and information retrieval tools such as catalogues, indexes etc. They stand to gain from the collective experience of other participants of the network. Through their experience, they can overcome their own problems while at the same time having access to wider and richer information products and services. Some of the important data networks are India's National Informatics Center's NICNET, INDONET, ERNET, the library networks are CALIBNET DELNET, INFLIBNET, Information and Library Network Centre -- "an autonomous Inter-University Centre (IUC) of University Grants Commission involved in creating infrastructure for sharing information among academic and R\&D Institutions.

\subsection{Others}

The central challenge for librarians from developing countries in the digital age would be to bridge the digital divide. A clearly defined information technology policy is critical to the development of the IT infrastructure that would ensure information and knowledge migration into digital formats. But the information and knowledge resources must be in machine-readable formats. As more and more libraries in developing move to the electronic frontier, their librarians would have the 
dual responsibility of not only managing information but also the technology systems that enable the information production, - processing provision chain. Arthur Andersen (1998) they would emerge as:

- Technology experts -- ensuring that members of the knowledge communities Understand the available technology and use it to its fullest potential. This role is a technology trainer and cheerleader.

- Guides -- directing members of the knowledge community to outside information when appropriate and maintaining high-level information about sources outside the community.

- Scouts -- ferreting out information useful to the knowledge community and bringing it into the knowledge base.

- Research librarians -- helping users define information needs and prioritizing highly relevant information from a pool of interesting information according to user preferences.

- Analysts -- adding value to information by creating a context for understanding and by looking for pattern of information that points to new arrears of interest.

- As information providers -- librarians can make available much more widely collections which now can be used not only within a single physical library location. A wide range of publications and access formats can be accommodated, from remote login catalogues and indexes, to provision of electronic copies of entire collection or works, in print or other formats.

- Steeply rising unaffordable prices

- Unfair licensing Schemes

- Excessive Profits

Libraries and users in developing countries are most severely affected by these conditions, even the wealthiest research libraries in the developed countries are affected. This includes not only developing the basic telephone and telecommunication services, but also ensuring these service are provided at the lowest cost, as well as promoting the application of ICT $\mathrm{s}$ to facilitate improvements in the efficiency of the delivery information goods and social activities. In the last few years emergence of digital media, a variety of alternatives the above have come forward. These include:

- Not for profit aggregators (elfl)

- Open access journals 
- Institutional Repositories

In the information society, free flow of information is a fundamental principle for bridging the knowledge gap between privileged and under-privileged communities. Social inclusion (books for all) and economic empowerment are also achieved in a society where citizens have universal access to information and knowledge ranging from public information to specialized or customized related to one's profession or culture. The emerging economies amongst the developing countries are not for behind in building up necessary information infrastructure, essential economic development. These emerging countries, however, have limitations in terms of bridging the digital divide within their societies, due to co-existence of marginalized and privileged communities. With the availability advanced information and communication technologies (ICTs) and by building up necessary information infrastructure in South Asia, particularly India, this sub region becomes an active contributor to global open access literature. In this presentation we consider the impact on the user by five laws of library science, with an emphasis on current research. While the concept of a digital library can be traced the Vannear Bushs's Memex, (2) Library of the future, Nelson (3) hyperspace and Lancaster's paper less society.

\section{Conclusion}

In the Knowledge society, creation, building and developing knowledge infrastructure, is one of the main functions before the government and others. The Professional associations, especially national library associations have a greater role to play in this context. Libraries since the early ages of civilization are engaged in the process of preserving knowledge for posterity. These statements appear to be too simple but in reality these laws are quite complicated. These provide guidance and rationale for practice and teaching of Library and Information Science. The laws have been useful in teaching of different branches of Library Science. These have made an impact on the growth and development of theory and practice. These will serve as source of inspiration and guidance in the years to come. Every student and teacher of library science, librarian must give thought to the implications of these laws. Ranganathan, way was a constant analysis and codification of the details of the best professional practice in a never-ending search for fundamental principles as a guide to action. Applied in an appropriate manner, such principles would ensure that Indian LIS would rank with the best in the world, and contribute in a unique and systematic way to 
its forward progress. Today they have major role to play, as the knowledge society concept has widened to entire population of a nation and the professional associations have to be pro-active, to join hands with others, the NGOs and Government, to participate in the social development work. The ICT has provided for an excellent facility in this regard, through various avenues, such as web portals, blogs and so on. The Library associations have, through the services provided by their members, understood the informational needs of the society. The Information Literacy programmes which were confined to the four walls of the Libraries hence before, can now be spread across the length and breadth of the society, to empower the society to search and gather its own information. It is envisaged that the national associations in the knowledge society will enable and empower the professionals to promote the use facilities within the libraries and how to make the libraries a national asset. Associations will also set the mind set of the members that though their role is changed in the event of fast growth of Internet, they will be more necessary than ever for the healthy growth of the knowledge society. All said and done, if librarians are united in the association the intellectual capacity of the country can be enhances in many folds and foster this essential resource for the $21^{\text {st }}$ century.

\section{References}

[1] Aliraza, N. 2004. "Application of Ranganathan's Laws to the Web." Webology, 1(2).

[2] Cochrane, P. A. 2006. Putting Knowledge to Work: An American View of Ranganthan's Five Laws of Library Science. New Delhi: Ess Ess Publications.

[3] Dahlman, C. \& Utz, A. 2005. India and the Knowledge Economy: Leveraging Strengths and Opportunities. Washington: World Bank.

[4] Gopinath, M. A. 1985. "Guidelines for the formulate of a national information policy." In Building Library Collection and National Policy for Library and Information Science, $38^{\text {th }}$ All India Library Conference, Jaipur, India.

[5] Gorman, Michael. 1998. "The Five Laws of Library Science: Then \& now." School Library Journal.

[6] Kumar, P. S. G. 1992. Ranganathan: A Multi Faceted Personality. New Delhi, D.K.: Publishing Corporation.

[7] Lor, P. J. \& Britz J. J. 2007. "Challenges of the approaching knowledge society: Major international issues facing LIS professionals." Libri, 57: 111-122.

[8] Morrison, H. 2009. Scholarly Communication for Librarians. New Delhi: Chandos Publishing. 
[9] Neelameghan, A. 1997. "Dimension in information management: Ranganathan revisited." Library Slant to Documentation, 29.

[10] Patel, Jashu, \& Kumar, Krishan. 2004. Libraries and Librarianship in India. London: Green Wood Press.

[11] Ranganathan, S. R. 1931. Five Laws of Library Science, Madras: Madras Library Association. 